\title{
Diagnostic performance of 320 cardiac MDCT angiography in assessment of PDA either isolated or associated with duct dependent congenital heart disease
}

\author{
Samar Abdelatty Gad, Ekhlas Abdelmonem Shaban, Mohammed Mahmoud Dawoud ${ }^{*}$ and
} Mohamed Ahmed Youssef

\begin{abstract}
Background: Patent ductus arteriosus (PDA) is one of most common congenital heart defects, it's a unique vascular structure that provides direct communication between pulmonary and systemic circulation. MDCT angiography is a good imaging modality for evaluation of the PDAs and detection of their exact morphological type; course and diameters, which is important before percutaneous closure or stenting procedure of the PDA, also for selection of closure hardware. The aim of this study was to assess the role of MDCT angiography in qualitative and quantitative evaluation of PDA and associated cardiac and $\backslash$ or extracardiac anomalies.

Results: Echocardiography detected PDA in $28 \backslash 30$ cases while cardiac MDCT detected PDA in all studied 30 cases confirmed by cardiac catheterization and/or operation. MDCT angiography had sensitivity $100 \%$ and specificity 100\% for PDA detection. PDA originated from aortic isthmus in 15 cases, inferior surface of aortic arch in 11 cases and innominate artery in 4 cases. The most common morphological type of PDA was type A (cone\46.67\%) followed by type C (tubular $23.3 \%$ ), type D (complex\10\%), type E (elongated $13.33 \%$ ) and type B (window $6.67 \%$ ). The spearman correlation coefficient test demonstrated poor correlation between size of aortic end and MPA $(P=0.75)$, and between size of pulmonary end and diameter of MPA $(P=0.99)$ and also demonstrated fair correlation between length of PDA and MPA ( $P=0.018)$. PDA was isolated in $4 \backslash 30$ cases and associated with cardiac and $\backslash$ or extra cardiac anomalies in 26\30 cases included; ASD $(n=18)$, VSD $(n=16)$, pulmonary atresia $(n=7)$, transposition of great arteries $(n=5)$, teratology of Fallot $(n=4)$, aortic coarctation $(n=4)$, persistent truncus arteriosus $(n=3)$, tricuspid atresia $(n=3)$, anomalous of pulmonary venous return $(n=3)$, hypoplastic segment of aorta $(n=2)$, Ebstein's anomaly $(n=1)$, bicuspid aortic arch $(n=1)$ and left hypoplastic heart syndrome $(n=1)$.
\end{abstract}

Conclusion: Cardiac MDCT angiography was superior to Echocardiography in detection, quantitative and qualitative evaluation of PDA either isolated or associated with congenital cardiac and \or extracardiac anomalies and was superior to Echocardiography in detection of associated extracardiac anomalies rather than associated intra cardiac anomalies.

Keywords: Ductus arteriosus, PDA, Cardiac MDCT, Congenital heart disease

*Correspondence: dr.m.dawoud82@gmail.com

Radiodiagnosis and Medical Imagining, Faculty of Medicine, Tanta

University, El-geish street, Tanta, Gharbya Governorate, Egypt

\section{Introduction}

Congenital heart disease (CHD) is considered a major cardiac problem in pediatrics. Patent ductus arteriosus (PDA) represents $5-10 \%$ of all congenital malformations 
and considered one of the most common congenital heart defects in premature infants $[1,2]$.

Ductus arteriosus is a vascular communication between pulmonary and systemic circulations. The ductus arteriosus during fetal life diverts blood towards the descending aorta and placenta away from the fluid filled lungs, constriction of the ductus arteriosus and obliteration of its lumen after birth separate the pulmonary and systemic circulations [3].

Failure of closure of ductus arteriosus in some infants lead to persistent communication between aorta and pulmonary arteries, left to right extra cardiac shunting occur which depends on size of PDA and pulmonary vascular resistance. Congestive heart failure (CHF) may occur in medium and large shunts due to increased pulmonary blood flow and volume overload of the left heart [4].

PDA may present as isolated or associated with other cardiac and extra cardiac anomalies like tricuspid atresia, pulmonary atresia, teratology of Fallot, in these cases PDA is important for oxygenation and post-natal ductus constriction lead to severe hypoxia and cyanosis. Also, it may be associated with severe systemic blood flow restriction like aortic coarctation, aortic stenosis, interrupted aortic arch or left hypo plastic syndrome [5].

Cardiac imaging plays an important role in the diagnosis, management and follow up after surgical procedures [6]. Echocardiography is always the first line study of choice for neonates with congenital heart disease, it provides immediate high- resolution anatomical and physiological information in addition to its safety, speed, noninvasiveness, and easy availability. The main disadvantages were it is operator dependent and the image quality can be degraded in uncooperative children or by poor acoustic window $[7,8]$.

MDCT and Cardiac Magnetic Resonance Imaging (cMRI) provide valuable noninvasive imaging tools, they are helpful in assessing the complex cardiovascular morphology especially the extracardiac association as well as pulmonary artery anatomy and aortopulmonary collateral vessels [9]. Noninvasive imaging of PDA remains a challenge. MDCT angiography enables excellent qualitative and quantitative information of PDAs [10].

Cardiac Magnetic Resonance Imaging (cMRI) can provide both functional and anatomical information. Its use is limited in uncooperative or severely ill pediatric patients, and it is contraindicated in patients with pacemakers. Also, it takes longer time than $\mathrm{CT}$ and may require general anesthesia especially in patients less than 5 years old. In addition, the images available do not have the necessary spatial resolution to assess small anatomical structure [11].

Conventional angiography acts as the gold standard cardiac imaging tool. However, it is an invasive method which may cause death in up to $1 \%$ of neonates with complex CHD [12].

Multidetector CT enables a detailed evaluation of PDA morphology and size, potential complications such as thrombosis, aneurysms and calcifications which were useful in the diagnosis of PDA, planning of PDA percutaneous closure. MDCT also enables quantitative evaluation of great vessels morphometry including potential pulmonary artery hypertension and Eisenmenger syndrome [13].

Multidetector CT is easy and achievable now with sub $\mathrm{mSv}$ doses with short acquisition time minimizing the need for general anesthesia in pediatric imaging. It is helpful when dealing with clinically unstable children especially from intensive care setting [14]. Multiplanar and three-dimensional (3D) images reformatted from multi-slice spiral CT data can demonstrate normal and pathologic cardiovascular structures in patients with congenital heart disease [11].

The aim of this study was to assess the role of cardiac MDCT angiography in qualitative and quantitative evaluation of PDA and associated cardiac and $\backslash$ or extracardiac anomalies.

\section{Methods \\ Study population}

This prospective study was conducted on 30 cases suspected to have PDA by clinical examination or echocardiography referred from Pediatric cardiology and Cardio-thoracic departments to Radio-diagnosis and medical imaging department between March 2020 to April 2021 for assessment of PDA and its associated cardiac and $\backslash$ or extra cardiac anomalies.

Patients unwilling or lost for follow up, patients with allergy to the iodinated contrast material, and impaired renal function (creatinine level $>1.5 \mathrm{mg} / \mathrm{dl}$ ) were excluded from study.

Privacy and confidentiality of all patient's data were guaranteed and their coded number for every patient's file that include all investigations.

\section{All patients submitted to the following Study planning}

- All the patients had Echocardiographic reports of suspected or diagnosed PDA and underwent MDCT angiography of the heart and great vessels to confirm the diagnosis or to answer specific anatomic question raised by inconclusive echocardiography findings before planning the adequate management.

- Our gold standard in study was cardiac catheter or surgery. 
- Review of Echocardiographic findings and consultation with the referring physician was attempted prior to the study to discuss the clinical background of the case.

- Checking renal functions to exclude patients with impaired renal function.

- Proper history taking from the parents.

\section{Preprocedural preparations}

- Reassurance of the parents by description of the procedure to them.

- Placing of intravenous cannula (20-to 24-gauge) in the right upper limb vein (13 cases), or in a lower limb peripheral vein (17 cases).

- There was no need for general anesthesia in this study. Cases below 4 years $(n=27)$ were orally sedated by administration of chloral hydrate $(n=23)$ (50-100 mg/kg; maximum dose, $2000 \mathrm{mg}$ ) or I.V. administrated Midazolam $(n=4) \quad(0.05-0.1 \mathrm{mg} / \mathrm{kg})$. Older cases $(n=3)$ were responding satisfactorily to verbal reassurance to be able to completely suspend respiration.

\section{Technique of cardiac MDCT Examination}

Image acquisition

- Patients were scanned using 320-row multidetector CT scanner (Aquilion One, Toshiba Medical Systems, Otawara, Japan).

- The patient lay supine on the CT table, proper positioning of the patient on table was done to ensure the heart lies in the iso-center of the gantry for spatial resolution optimization.

- Application of ECG electrodes to chest wall after skin preparation with alcohol.

- Insertion of the intravenous (IV) line and injection testing with saline was done to ensure good IV access with no extravasation.

- Thereafter, obtaining of a scanogram (frontal \& lateral views) where the scan ranges from neck root entailing proximal common carotid and subclavian arteries down to the level of portal vein inferiorly.

- Non-ionic, non-diluted contrast material (Ultravist 300, Schering AG, Germany or Omnipaque 300, Nycomed, Amersham) was injected in 28 and 2 patients respectively according to body weight with maximum dose was $2 \mathrm{ml} / \mathrm{kg}$ through the peripherally inserted IV cannula using dual syringe mechanical power injector (Stellant D, Medrad, Indianola, PA,
USA) with flow rate $1-1.5 \mathrm{ml} / \mathrm{sec}$ increased to $3 \mathrm{ml} /$ sec in older children.

- IV saline chaser injection of $1 \mathrm{ml} / \mathrm{kg}$ was given immediately after the contrast injection to improve the contrast homogenicity and opacification.

- Manual Bolus tracking was applied after 10-15 s from contrast material injection timing (for upper limb venous line) and after $20 \mathrm{~s}$ (for lower limb venous line), the scan is initiated after opacification of both ventricles.

- All scans were performed in the cranio-caudal direction, with CT parameters adapted to the patients' weight. The patients were scanned using a singlephase retrospective ECG gated CTA volume scan with a rotation time of $0.35 \mathrm{~s}$ and a tube voltage of $80 \mathrm{kV}$ increased to $100 \mathrm{kV}$ in 3 older children. The quality of images was reviewed before end of examination.

- The patient was kept under observation for 15-30 min till recovery of sedation.

Image reconstruction and post processing Full volumes were reconstructed in $0.5 \mathrm{~mm}$-thickness slice. Post-processing of multi-detector CT (MDCT) scans was performed by dedicated remote workstation (Vitrea Fx, Vital Images, USA).

\section{Image interpretation}

Images were interpreted guided by the anatomical and segmental/sequential approach as follows:

- Heart: situs: solitus/inversus/ambiguous. Atrio-ventricular concordance/discordance. Ventriculo-arterial concordance/discordance. Interaterial septum: intact/ASD (type, size). Interventricular septum: intact/VSD (type, size). Size and morphology of the cardiac chambers. Presence of intracardiac masses or thrombi. Presence of pericardial effusion.

- PDA: Origin: inferior surface of aorta/aortic isthmus/ innominate artery. Type: A/B/C/D/E. Left/right sided PDA. Tortuosity type of PDA: I/II/III.

- Aorta: origin: left ventricle/right ventricle. Size: nor$\mathrm{mal} / \mathrm{small} / \mathrm{enlarged}$.

- Aortic Arch: site: left sided/right sided. Size: normal /small/enlarged. Anomalies: Coarctation/ interruption/ double/hypoplastic. Branching pattern: normal/ bovine arch/ aberrant right subclavian artery/ aberrant left subclavian artery.

- Pulmonary arteries: origin and size: normal / dilated/ small/ atretic.

- Major pulmonary collaterals or dilated bronchial arteries. 
- Pulmonary venous drainage: size /anomalies of drainage.

- Systemic venous drainage: the superior and inferior venae cavae drainage. Confirm or exclude left superior vena cavae.

- Coronary arteries: adequately or inadequately assessed. Origin, course and abnormalities.

\section{Statistical analysis}

Statistical analysis of the present study was conducted by SPSS V.20. Qualitative data was presented using number and percentage. Quantitative data presented as mean and standard deviation (SD). For categorical variables, Chisquare test was used for analysis. The level of significance was adopted at $P<0.05$.

\section{Results}

This prospective study enrolled 30 cases; 16 (53.33\%) males and 14 (46.67\%) females, their ages ranged from 2 days to 18 years with a mean age of $20.223 \pm 53.132$ month. The most common age group was less than one month including 11 (36.67\%) cases followed by age group from 4 months $-<12$ months including 8 (26.67\%) cases, 1 month $-<4$ months including $7(23.33 \%)$ cases and $>12$ months including 4 (13.33\%) cases.

According to the clinical presentation of the studied cases, 2 of them were asymptomatic and the other 28 cases were symptomatic presented with cyanosis $(n=15)$, dyspnea $(n=8)$, poor feeding $(n=7)$, tachypnea $(n=13)$, recurrent chest infection $(n=5)$ and failure to thrive $(n=2)$.

All the patients had Echocardiographic reports of suspected or diagnosed PDA and underwent MDCT angiography of the heart and great vessels to confirm the diagnosis. We compared cardiac MDCT findings with the data collected by cardiac catheterization and/or operation (gold standard).

Echocardiography detected PDA in 28 cases (93.3\%) while MDCT angiography detected PDA in all studied 30 cases confirmed by cardiac catheterization and/or operation. MDCT angiography had sensitivity $100 \%$ and specificity $100 \%$ for PDA detection with the advantage of giving precise anatomical details and volume rendered images which are very helpful before surgery for accurate surgery planning.

\section{Qualitative and quantitative assessment of PDA by cardiac MDCT}

Twenty six cases had left sided PDA and 4 cases had right sided PDA. PDA originated from aortic isthmus in 15 cases (Fig. 1), inferior surface of aortic arch in 11 cases (Fig. 2, 3) and innominate artery in 4 cases (Fig. 4). The morphological type of PDA was evaluated according to Krichenko et al. classification [15], it was found that the most common type of PDA was type A (cone) detected in $14(46.67 \%)$ cases followed by type $C$ (tubular) detected in 7 (23.3\%) cases (Fig. 2,3), type D (complex) detected in $3(10 \%)$ cases, type $\mathrm{E}$ (elongated) detected in $4(13.33 \%)$ cases (Fig. 1) and type B (window) detected in 2 (6.67\%) cases (Fig. 5). According to tortuosity of PDA, it was straight (type I) in 15 cases, has one turn (type II) in 9 cases, and has multiple turns and tortuous (type III) in 6 cases.

The size of aortic end of PDA, pulmonary end of PDA, length of PDA, diameter of main pulmonary artery, diameter of aortic isthmus and descending aorta were calculated and compared according to the type of PDA as listed in Table 1.

The spearman correlation coefficient test demonstrated poor correlation between size of aortic end and MPA $(P=0.75)$, and between size of pulmonary end and diameter of MPA $(P=0.99)$. Fair correlation between length of PDA and MPA $(P=0.018)$. Also demonstrated poor correlation between size of aortic end and diameter of RPA $(P=0.57)$, between size of pulmonary end and diameter of RPA $(P=0.4)$, and between length of PDA and RPA $(P=0.12)$. The spearman correlation coefficient test demonstrated poor correlation between size of aortic end and diameter of LPA $(P=0.3)$, and between size of pulmonary end and diameter of LPA $(P=0.07)$. Fair correlation between length of PDA and LPA $(P=0.027)$, the above findings shown in Table 2 and Figs. 6, 7.

\section{Associated cardiac andlor extra cardiac anomalies with PDA}

Among the studied 30 cases, PDA was isolated in 4 (13.3\%) cases and associated with cardiac andlor extra cardiac anomalies in $26(86.6 \%)$ cases. Cardiac and extra cardiac anomalies associated with PDA detected

(See figure on next page.)

Fig. 1 A 1-month-old female patient presented with tachypnea and failure to thrive. a MDCT Coronal oblique MIP image showed PDA originate from aortic isthmus to LPA proximal segment, $\mathbf{b}$ Axial MIP image showed PDA connect between aortic isthmus and LPA with atretic MPA, $\mathbf{c}$ Axial MIP image showed coronary fistula with hypoplastic right ventricle, $\mathbf{d}$ Axial MIP image showed left sided aortic arch with aberrant RT SCA, e VR image showed PDA with type II tortuosity, $\mathbf{f} \vee R$ oblique lateral image showed PDA connecting aortic isthmus with proximal segment of LPA, $\mathbf{g} \vee R$ anterior view of the heart showed cameral fistula between right coronary artery and hypoplastic right ventricle, $\mathbf{h} \vee R$ oblique lateral view showed type $E$ PDA originate from aortic isthmus to LPA. A case of hypoplastic right ventricle with pulmonary atresia and duct dependent pulmonary circulation 

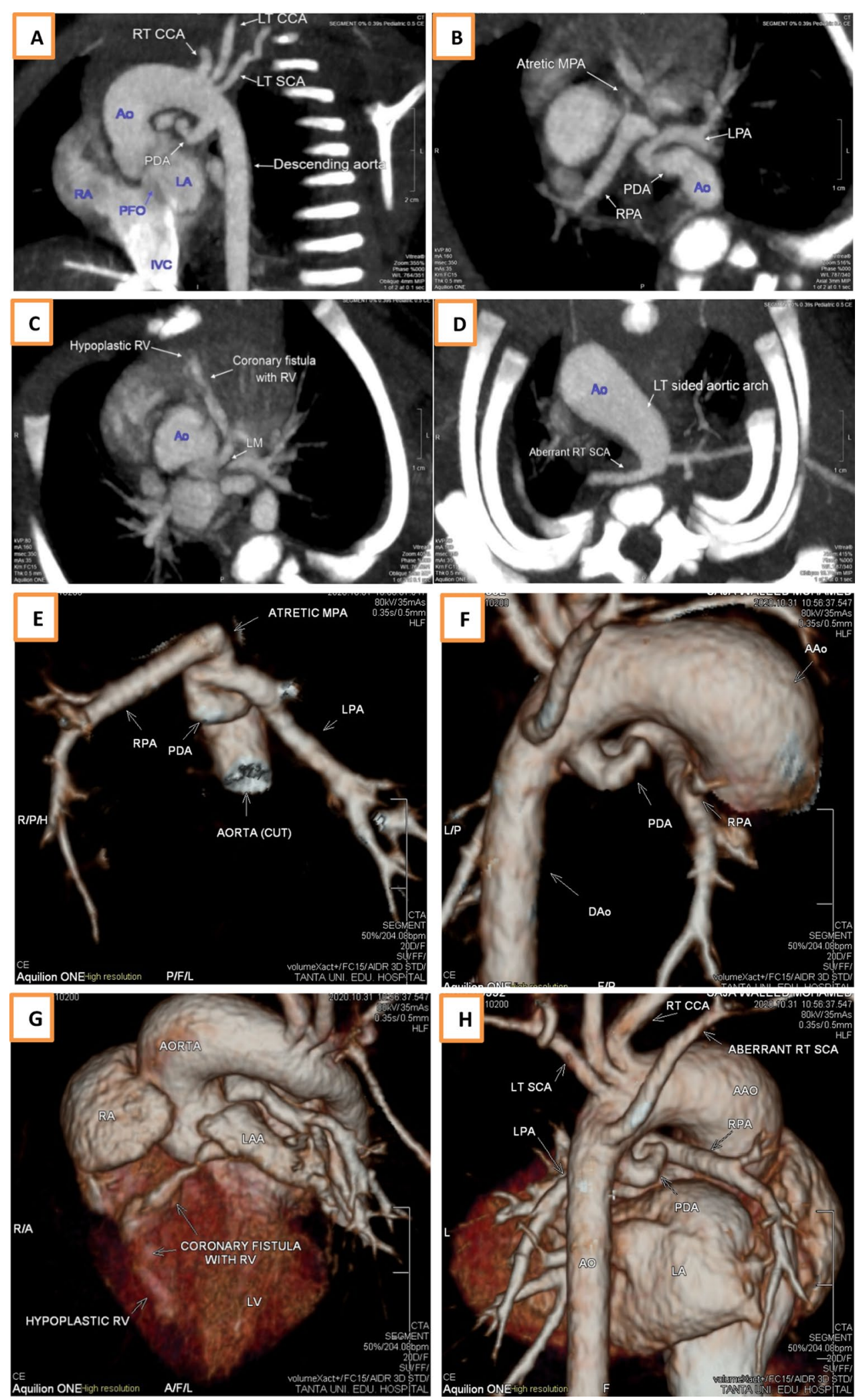

Fig. 1 (See legend on previous page.) 

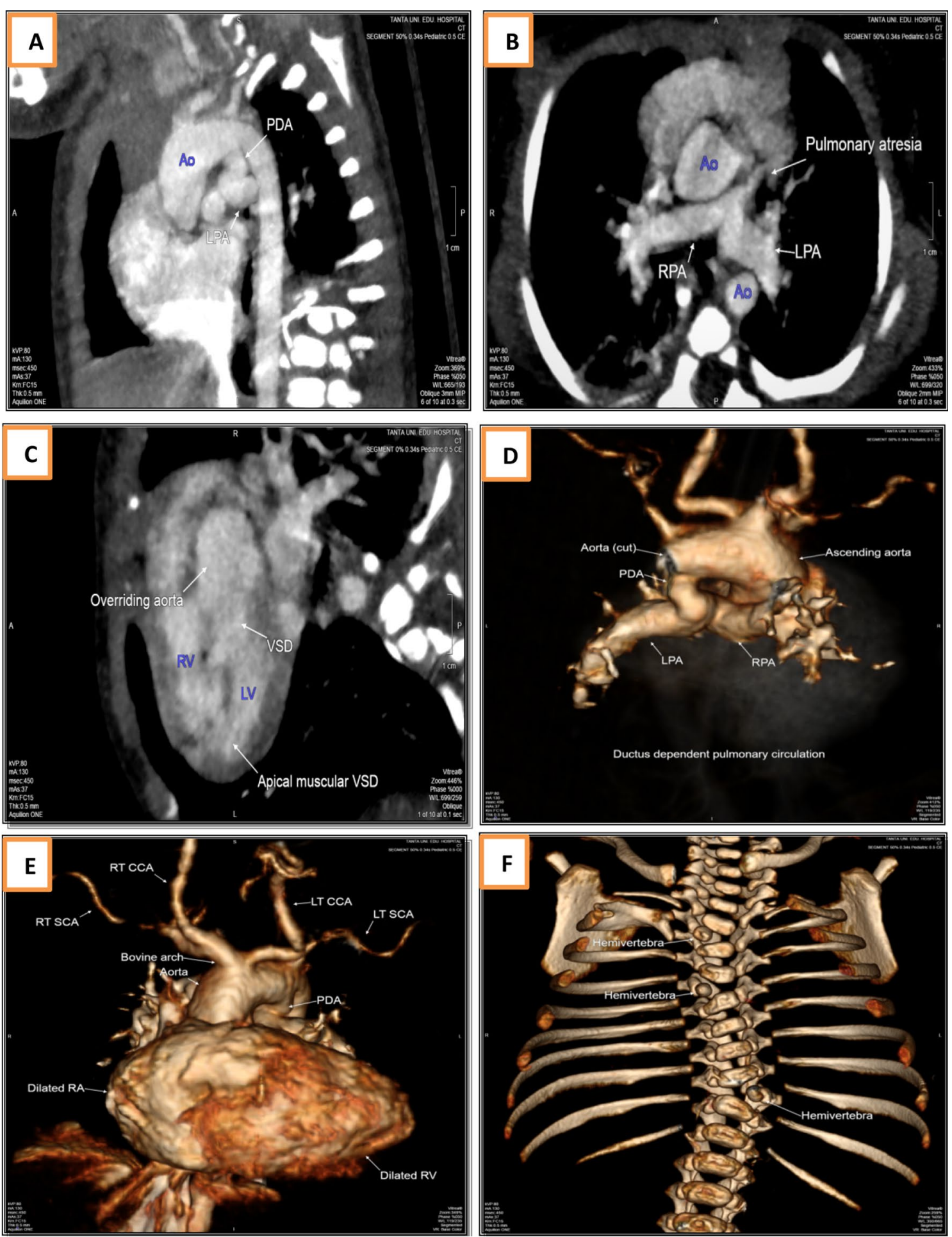

Fig. 2 A 4-day-old male patient presented with tachypnea and cyanotic spills. a MDCT Sagittal MIP image showed tortuous PDA originated from undersurface of distal aortic arch to LPA without stenosis (type C), b Axial MIP image showed atretic MPA with sizable RPA \& LPA, c Oblique reformatted image showed overriding aorta, perimembranous outlet VSD and apical muscular VSD, d VR image showed PDA connecting between aortic arch and LPA, eVR image showed bovine branching pattern of aortic arch, PDA origin and dilated right sided cardiac chambers, $\mathbf{f} V R$ image showed Scoliotic deformity of dorsal spine with three dorsal hemivertebrae. A case of pulmonary atresia with duct dependent pulmonary circulation 
by MDCT angiography included; ASD $(n=18)$, VSD $(n=16)$ (Figs. $2,4,5)$, pulmonary atresia $(n=7)$ (Fig. 4), transposition of great arteries $(n=5)$, teratology of Fallot $(n=4)$, aortic coarctation $(n=4)$, persistent truncus arteriosus $(n=3)$, tricuspid atresia $(n=3)$, anomalous of pulmonary venous return $(n=3)$, hypoplastic segment of aorta $(n=2)$, Ebstein's anomaly $(n=1)$, bicuspid aortic arch $(n=1)$ and left hypoplastic heart syndrome $(n=1)$.

The associated anomalies were divided according to duct dependent lesions into duct dependent pulmonary circulation lesions (15 cases), duct dependent systemic circulation lesions (7 cases) and duct dependent lesions with combined mixing blood between systemic and pulmonary circulation (5 cases) with TGA. These associated anomalies are illustrated at Table 3.

\section{Intra-cardiac anomalies associated with PDA}

The intracardiac defects encountered within the study were classified into atrial and ventricular septal defects. The most common ventricular septal defect (VSD) was perimembranous VSD (8 cases, 26.6\%). The most common atrial septal defect (ASD) was ostium secundum ASD (12 cases, 40\%).

Cardiac MDCT missed the diagnosis of ASD in 1 case and VSD in 1 case, hard to interpret ASD in 1 case and VSD in 2 cases due to cardiac motion during the examination and accurately diagnosed other types of ASD and VSD. Chi square test revealed non statistically significant difference between Echo and MDCT angiography in detection of ASD $(P=0.95)$ and VSD $(P=0.90)$ as listed in Table 4.

\section{Extra-cardiac anomalies associated with PDA}

Regarding aortic anomalies (Figs. 3, 5), Echocardiography missed aortic coarctation in 1 case, hypoplastic aortic segment in 3 cases, right sided aortic arch in 3 cases. However, MDCT angiography missed one case of aortic valve stenosis due to motion artifact that interfere with good interpretation of aortic valve anatomy as listed in Tables 5 and 6.

Different aortic arch branching patterns were detected by MDCT angiography; left sided aortic arch with normal branching pattern $(n=18)$, left sided arch with bovine branching pattern $(n=6)$, right sided aortic arch with mirror image branching pattern $(n=3)$, left sided with aberrant right subclavian artery $(n=1)$ (Fig. 1), and right sided aortic arch with aberrant left subclavian $(n=1)$.

Regarding coronary arteries anomalies, twenty-two cases had no coronary anomalies, 5 cases were hard to be interpretable due to motion artifact (high heart rate), 2 cases had single coronary artery and 1 case had ectatic left coronary artery with cameral fistula end at right ventricle (Fig. 1).

Regarding main pulmonary artery abnormalities (Figs. 1, 2), MDCT angiography detected pulmonary atresia in $4(13.33 \%)$ cases, dilated MPA in 7 (23.33\%) cases, MPA hypoplasia in $6(20 \%)$ cases, subpulmonic stenosis in $1(3.33 \%)$ case. While Echocardiography missed detection of two cases with pulmonary atresia, 1 case with sub pulmonic stenosis, 1 case of hypoplastic MPA and 1 case with dilated MPA. Chi square test revealed non statistically significant difference between both Echocardiography and cardiac MDCT in detection of main pulmonary artery anomalies. Regarding right pulmonary artery abnormalities, MDCT angiography reported RPA hypoplasia in $7(23.3 \%)$ cases, ostial stenosis in $3(10 \%)$ cases, dilated RPA in 7 (23.33\%) cases. Echocardiography failed to diagnose 3 cases with dilated RPA, 3 cases with RPA hypoplasia and 3 cases with osteal stenosis. Regarding left pulmonary artery abnormalities, MDCT angiography revealed LPA hypoplasia in $8(26.67 \%)$ cases, ostial stenosis in 4 (13.33\%) cases, dilated LPA in 7 (23.3\%) cases. Echocardiography failed to diagnose 5 cases with hypoplastic LPA, 3 cases with LPA osteal stenosis and 2 cases with dilated LPA.

Chi square test revealed statistically significant difference between Echocardiography and cardiac MDCT in detection of left pulmonary artery and right pulmonary artery anomalies $(P=0.05$ for left pulmonary artery and $P=0.043$ for right pulmonary artery) as listed in Table 7 .

Cardiac MDCT missed diagnosis of one case with pulmonary stenosis and 2 cases with hypoplastic pulmonary artery branches due to cardiac motion which degrade the quality of the image as listed in Table 8 .

Regarding pulmonary venous abnormalities, pulmonary veins were normal in 27 cases and venous anomalies were diagnosed in 3 cases; (TAPVR) total anomalous pulmonary venous return detected in $1(3.33 \%)$ case, (PAPVR) partial anomalous pulmonary venous return

(See figure on next page.)

Fig. 3 A 1-month-old male patient presented with poor feeding and dyspnea. a MDCT VR oblique anterior view showed PDA arising from inferior surface of the aorta connected to MPA, $\mathbf{b}$ VR oposterior view showed PDA connected to dilated MPA, $\mathbf{c}$ VR oblique posterior view showed hypoplastic aortic arch with focal coarctation seen at the aortic isthmus, $\mathbf{d}$ VR oblique posterior view showed normal branching pattern of the aorta, e axial MIP view showed pulmonary end of PDA and also persistent left SVC is seen, f Sagittal MIP image showed type C (tubular) PDA connecting between MPA and inferior surface of aortic arch, $\mathbf{g}$ Coronal MIP image showed focal aortic isthmus coarctation with hypoplastic aortic arch, $\mathbf{h}$ Short axis view showed dilated right ventricle, $\mathbf{i}$ Coronal MIP image showed normal pulmonary venous return. A case of aortic coarctation with duct dependent systemic circulation 

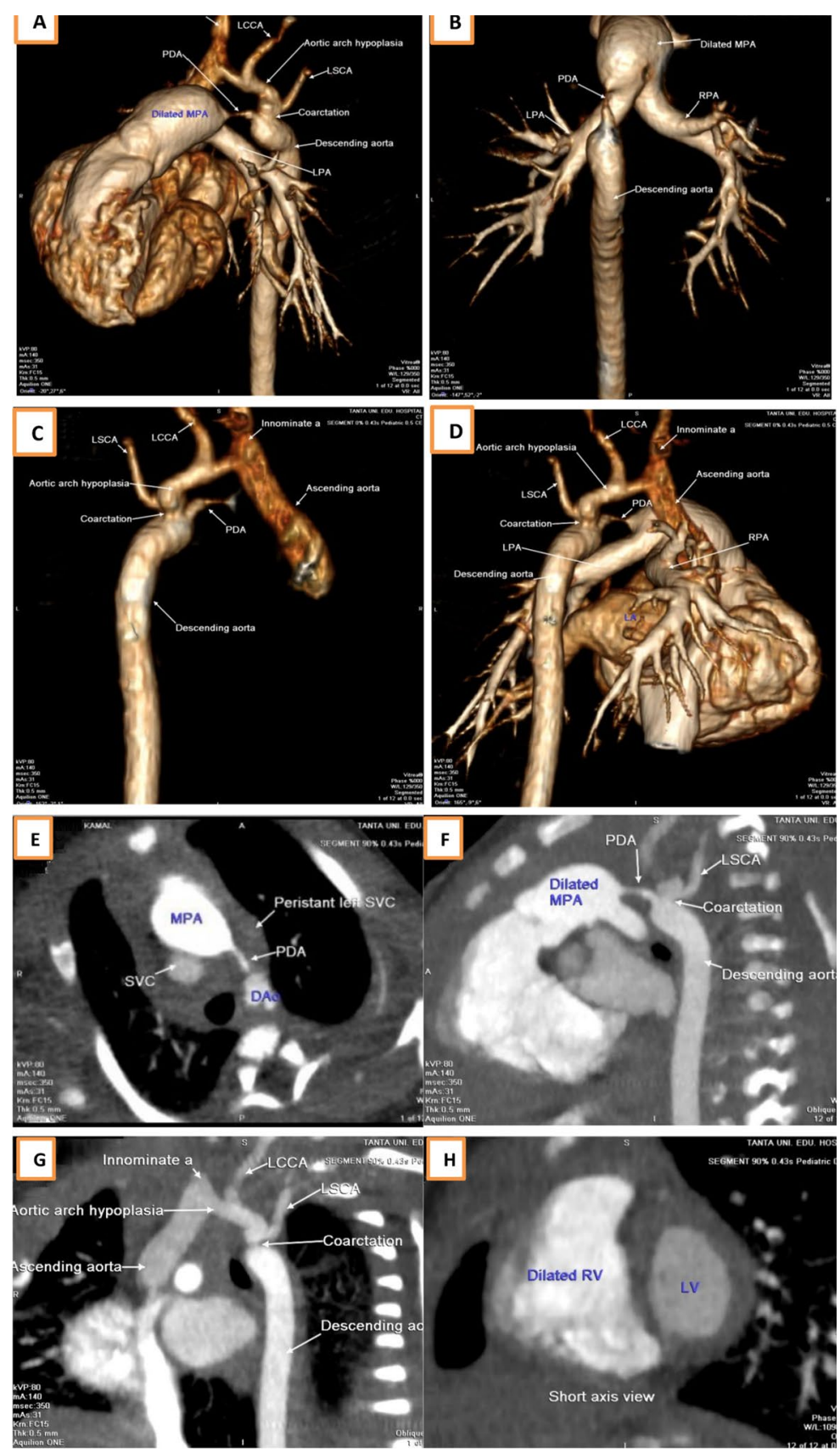

Fig. 3 (See legend on previous page.)

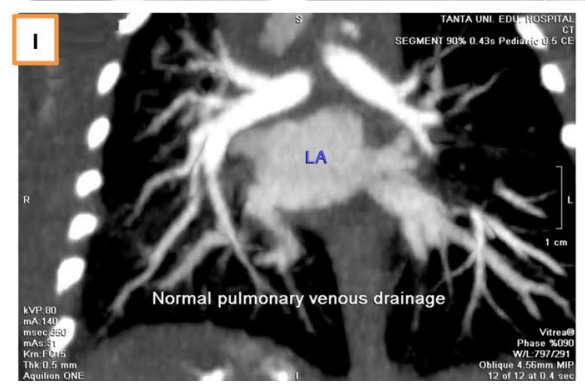


detected in 2 (6.66\%) cases. Echocardiography missed diagnosis of 2 cases with PAPVR. Chi square test revealed non statistically significant difference between both Echocardiography and MDCT in detection of pulmonary venous anomalies $(P=0.262)$.

Regarding systemic venous anomalies, cardiac MDCT detected four cases with double SVC and one case with left sided SVC. Echocardiography missed detection of double SVC in 3 out of 4 cases.

\section{Radiation dose}

The MDCT scanner automatically estimated the absorbed radiation dose in the form of dose length product (DLP) (radiation dose for a predetermined scanned length). For transforming the DLP to effective radiation dose in milliSievert, it is agreed to multiply the DLP by conversion coefficient factor according to age. Thirty MSCT examinations were done, and the mean absorbed radiation dose was $91.79 \pm 88.45$ mGy per scan and the mean effective dose was $2.61 \pm 1.38 \mathrm{mSv}$ as illustrated in Table 9.

\section{Discussion}

PDA could be seen isolated or associated with other congenital cardiac and $\backslash$ or extra cardiac anomalies. A detailed description of the PDA is important before attempting percutaneous closure of the PDA and during selection of closure hardware [16].

Cardiac catheterization was traditionally used to complement Echocardiography and to visualize extracardiac great vessels and remains the gold standard for direct hemodynamic assessment [17]. Cardiac MDCT is an important modality used for the accurate depiction of complex cardiovascular anatomic features before and after surgery [18].

Potential interventional complications (dissection, occlusion, bleeding, etc.) with cardiac catheterization are absent in cardiac MDCT, also it is applicable in the case of bleeding diathesis. Conventional angiography has the disadvantage of being invasive, taking a long time, and requiring anaesthesia in the paediatric population. However, hemodynamic information such as pressure curves and oxygen saturation data cannot be derived from MDCT examination [19].

The presence of clinical symptoms in patients with PDA is related to the magnitude of the shunt through the duct [11], in the present study we found two cases of the studied cases were asymptomatic and the other 28 cases had symptoms.

In the current study, Echocardiography missed detection of two cases of PDA, this came in agreement with $\mathrm{Hu}$ et al. [20] and Nie et al. [21], they stated that Echocardiography can only identify relatively large ones, in contrast to study did by Eltatawy et al. [22], they reported that Echocardiography detect PDA in all cases of their study but overestimate one PDA.

Lin et al. [23] reported that PDA originated from inferior surface of aortic arch in all cases. However, in the present study we detected origin of PDA from aortic isthmus in 15 cases, from inferior surface of aortic arch in 11 cases and from innominate artery in 4 cases.

Krupinski et al. [13], documented the occurrence of type A PDA with a wide aortic and narrow pulmonary orifice in the majority of the cases (16 cases $\backslash 50 \%)$ followed by type $\mathrm{C}$ in 9 cases (28\%), also they reported that types D (with multiple constrictions) and type $\mathrm{E}$ (elongated with distal constriction) ducts were marginal and made up only a few percent of patients $(2 / 32) 6 \%$. Also, Morgan et al. [10] reported that most common type of PDA was type A. We reported in this study that type A PDA was the most common PDA type (14/30) represented $46.67 \%$ and type B was the least common type of PDA $(2 / 30)$ represented $6.67 \%$.

We reported larger aortic orifice than pulmonary orifice $(4.6 \pm 1.8 \mathrm{~mm}$ vs. $2.4 \pm 1.04)$ in type A PDA. This came in acceptance with Krupinski et al. [13], they provided quantitative evaluation confirmed the qualitative findings of larger aortic than pulmonary orifices in patients with the type A morphology of PDA $(10.2 \pm 5.2 \mathrm{~mm}$ vs. $5.1 \pm 2.7 \mathrm{~mm}, P=0.0001)$.

The spearman correlation coefficient test in this study demonstrated fair correlation between length of PDA and MPA $(P=0.018)$. Also demonstrated fair correlation between length of PDA and LPA $(P=0.027)$ which agreed with Krupinski et al. [13], they reported that diameters of PDA correlated with diameters of pulmonary artery and this correlation was strongest between PDA diameter at the narrowest site and diameter of main pulmonary artery.

Eltatawy et al. [22] reported 14 cases with PDA, only two of them were isolated with no intracardiac or another vascular anomaly. We noted in current study four cases were isolated PDA and 26 cases were associated with other cardiac and $\backslash$ or extra cardiac anomalies.

(See figure on next page.)

Fig. 4 A 15-day-old male patient presented with tachypnea and poor feeding. a MDCT Coronal MIP image showed right sided PDA originate from innominate artery to RPA, b Axial MIP image showed pulmonary atresia with sizable pulmonary artery branches, $\mathbf{c}$, $\mathbf{d}$ Reconstructed oblique images showed overriding aorta with subaortic VSD, e VR image showed type E PDA with type I tortuosity, f VR image showed normal branching pattern of the aorta, $\mathbf{g}$ VR image showed PDA connecting right innominate artery with proximal segment of RPA, $\mathbf{h} V R$ anterior view of the heart showed right sided PDA originating from innominate artery. A case of pulmonary atresia with duct dependent pulmonary circulation 

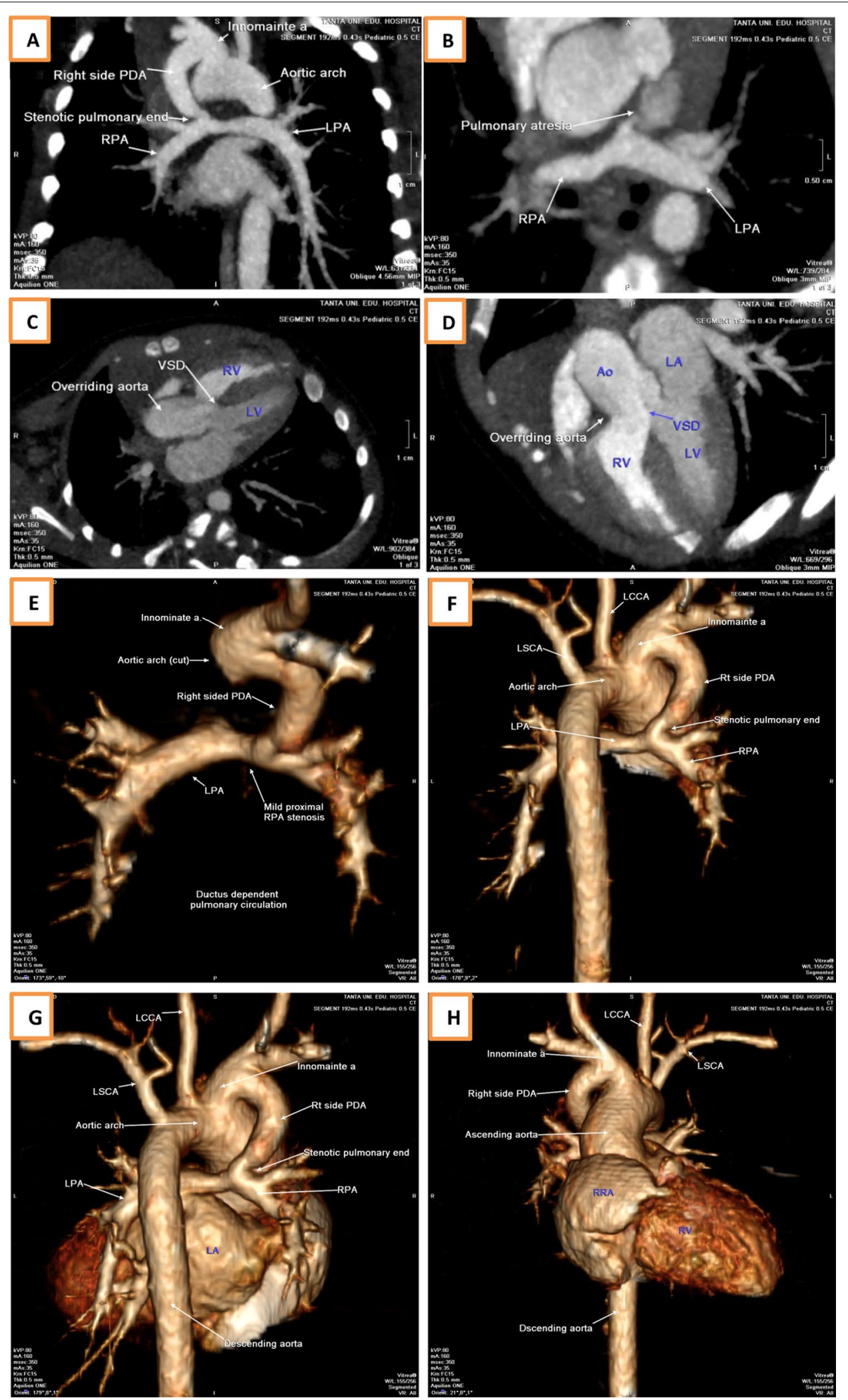

Fig. 4 (See legend on previous page.) 

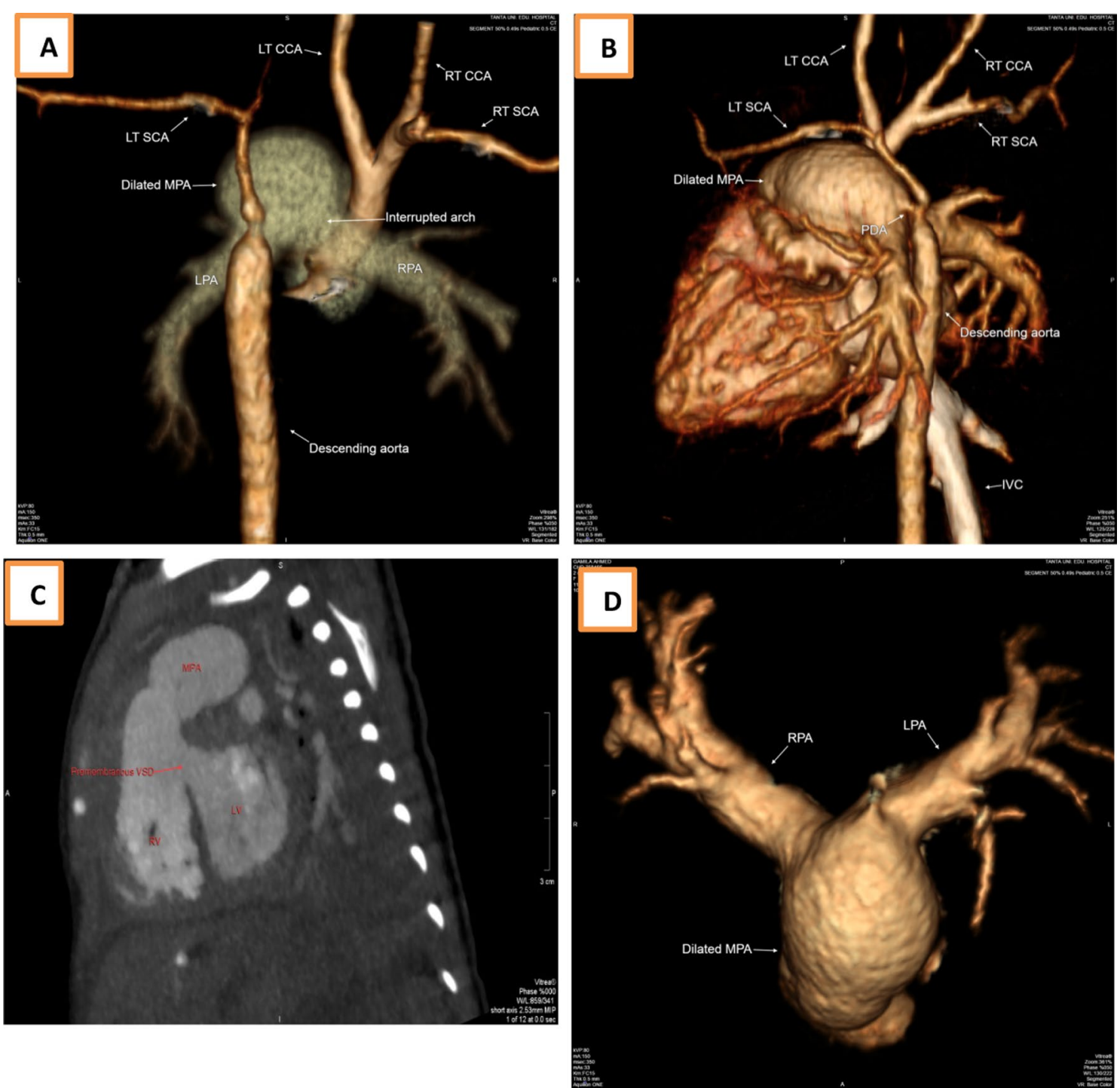

Fig. 5 : A 2-day-old female patient presented with cyanosis and poor feeding. a MDCT VR posterior view showed interrupted aortic arch proximal to left SCA, $\mathbf{b}$ VR oblique posterior view showed PDA connecting aortic isthmus to LPA, $\mathbf{c}$ Short axis MIP view of the heart showed perimembranous VSD, $\mathbf{d}$ VR image showed dilated MPA, LPA and RPA. A case of interrupted aortic arch with duct dependent systemic circulation

Table 1 Morphological types of PDA correlated with the size of PDA, pulmonary artery, and aortic diameters

\begin{tabular}{|c|c|c|c|c|c|c|c|}
\hline & \multicolumn{5}{|c|}{ Type of PDA by CT } & \multicolumn{2}{|c|}{ ANOVA } \\
\hline & A (cone) & B (window) & C (tubular) & D (complex) & E (elongated) & $F$ & $P$ value \\
\hline & Mean \pm SD & Mean \pm SD & Mean \pm SD & Mean \pm SD & Mean \pm SD & & \\
\hline Size of aortic end (mm) & $4.679 \pm 1.829$ & $1.750 \pm 0.354$ & $5.929 \pm 1.359$ & $4.325 \pm 1.615$ & $5.767 \pm 1.531$ & 2.920 & $0.041^{*}$ \\
\hline Size of pulmonary end (mm) & $2.423 \pm 1.041$ & $2.150 \pm 0.778$ & $3.843 \pm 2.174$ & $3.350 \pm 1.248$ & $3.333 \pm 1.290$ & 1.386 & 0.269 \\
\hline Length of PDA (mm) & $10.414 \pm 4.981$ & $2.000 \pm 0.000$ & $14.214 \pm 8.316$ & $13.425 \pm 3.820$ & $16.667 \pm 5.033$ & 2.565 & 0.063 \\
\hline Diameter of MPA (mm) & $11.250 \pm 7.119$ & $13.500 \pm 9.192$ & $9.000 \pm 6.030$ & $5.500 \pm 5.196$ & $8.700 \pm 2.404$ & 0.765 & 0.559 \\
\hline Diameter of RPA (mm) & $9.021 \pm 5.911$ & $7.000 \pm 1.414$ & $5.517 \pm 3.099$ & $6.525 \pm 3.233$ & $3.000 \pm 2.193$ & 1.302 & 0.298 \\
\hline Diameter of LPA (mm) & $8.143 \pm 6.094$ & $7.500 \pm 3.253$ & $5.114 \pm 2.477$ & $7.100 \pm 3.806$ & $4.167 \pm 1.332$ & 0.728 & 0.582 \\
\hline Diameter of descending aorta (mm) & $7.900 \pm 4.783$ & $8.500 \pm 3.536$ & $7.686 \pm 1.432$ & $7.375 \pm 1.601$ & $7.667 \pm 1.155$ & 0.037 & 0.997 \\
\hline Diameter of aortic isthmus (mm) & $8.043 \pm 6.618$ & $7.800 \pm 8.768$ & $7.671 \pm 3.924$ & $8.750 \pm 5.560$ & $12.167 \pm 3.686$ & 0.358 & 0.836 \\
\hline
\end{tabular}

* significant $p$ value $(<0.05)$ 
Table 2 Spearman's correlation between PDA diameters, pulmonary artery, and aortic diameters

\begin{tabular}{|c|c|c|c|c|c|c|}
\hline & \multicolumn{6}{|c|}{ Spearman's correlations } \\
\hline & \multicolumn{2}{|c|}{ Size of aortic end (mm) } & \multicolumn{2}{|c|}{ Size of pulmonary end (mm) } & \multicolumn{2}{|c|}{ Length of PDA (mm) } \\
\hline & $R$ & $P$ value & $R$ & $P$ value & $R$ & $P$ value \\
\hline Diameter of MPA (mm) & 0.064 & 0.752 & 0.002 & 0.992 & -0.451 & $0.018^{*}$ \\
\hline Diameter of RPA (mm) & 0.109 & 0.574 & -0.162 & 0.409 & -0.295 & 0.120 \\
\hline Diameter of LPA (mm) & -0.193 & 0.307 & -0.073 & 0.708 & -0.405 & $0.027^{*}$ \\
\hline Diameter of descending aorta (mm) & -0.011 & 0.954 & -0.103 & 0.594 & -0.167 & 0.378 \\
\hline Diameter of aortic isthmus (mm) & 0.004 & 0.984 & -0.140 & 0.470 & 0.021 & 0.914 \\
\hline
\end{tabular}

* significant $p$ value $(<0.05)$
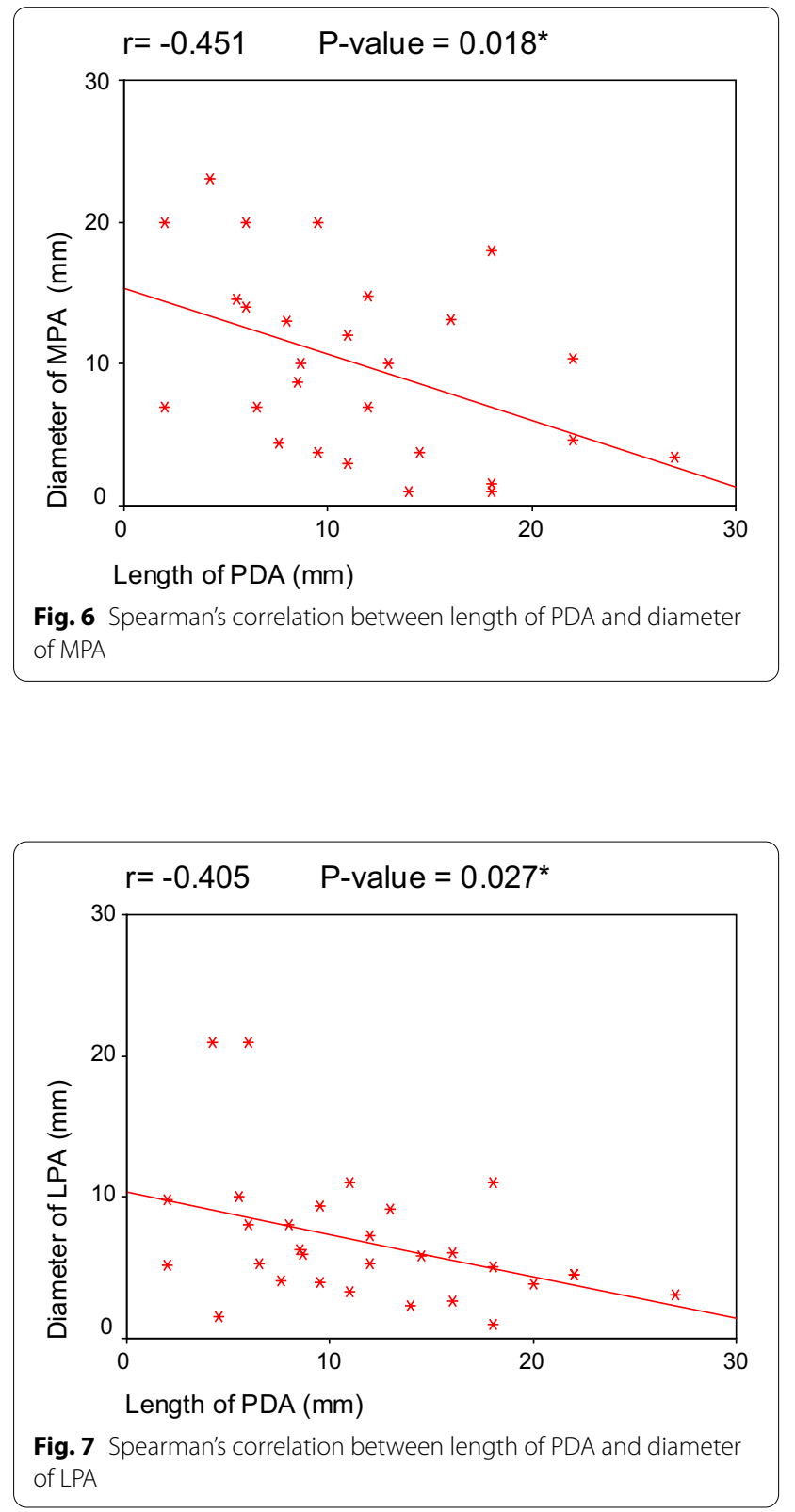

Table 3 Associated cardiac and extra cardiac anomalies with PDA in the studied patients $(n=26)$

\begin{tabular}{|c|c|c|c|c|}
\hline \multirow[t]{2}{*}{ Associated anomalies } & \multicolumn{2}{|c|}{$\mathrm{ECHO}$} & \multicolumn{2}{|c|}{ MDCT } \\
\hline & No & $\%$ & No & $\%$ \\
\hline \multicolumn{5}{|l|}{ Duct dependent pulmonary } \\
\hline Pulmonary atresia & 7 & 23.33 & 7 & 23.33 \\
\hline Tricuspid atresia & 2 & 10.00 & 2 & 10.00 \\
\hline TOF & 4 & 13.33 & 4 & 13.33 \\
\hline Ebstein's anomaly & 1 & 3.33 & 1 & 3.33 \\
\hline Critical pulmonary stenosis & 1 & 3.33 & 1 & 3.33 \\
\hline \multicolumn{5}{|l|}{ Duct dependent systemic } \\
\hline Aortic coarctation & 3 & 10.00 & 4 & 13.33 \\
\hline Critical aortic valve stenosis & 1 & 3.33 & 1 & 3.33 \\
\hline Hypoplastic left heart syndrome & 1 & 3.33 & 1 & 3.33 \\
\hline Interrupted aortic arch & 1 & 3.33 & 1 & 3,33 \\
\hline \multicolumn{5}{|l|}{ Duct dependent pulmonary and systemic } \\
\hline TGA & 5 & 16.66 & 5 & 16.66 \\
\hline \multicolumn{5}{|l|}{ Others } \\
\hline VSD & 18 & 40.00 & 16 & 36.66 \\
\hline ASD & 20 & 60.00 & 18 & 63.33 \\
\hline Truncus arteriosus & 3 & 10.00 & 3 & 10.00 \\
\hline Anomalous pulmonary venous return & 1 & 3.33 & 3 & 10.00 \\
\hline Persistent left SVC & 1 & 3.33 & 4 & 13.3 \\
\hline
\end{tabular}

Regarding associated cardiac and extra cardiac anomalies in the present study; 15 cases with duct dependent pulmonary anomalies, 7 cases with duct dependent systemic anomalies and 5 cases with duct dependent mixing circulation anomalies (TGA). However, in the study did by Lin et al. [23], they reported all cases of their study were duct dependent pulmonary circulation.

Enaba et al. [24], reported 15 cases of tetralogy of Fallot (25\%), 12 cases of tricuspid atresia (20\%), four cases of Ebstein's anomaly (6.5\%) and 7 cases of pulmonary atresia and stenosis (11.5\%). Also, Seif El-Din et al. [16] reported 4 cases of tetralogy of Fallot associated with PDA. 
Table 4 Interatrial septum and interventricular septum defects detected by Echocardiography and MDCT angiography

\begin{tabular}{|c|c|c|c|c|c|c|}
\hline & \multicolumn{2}{|c|}{$\mathrm{ECHO}$} & \multicolumn{2}{|c|}{ MDCT } & \multicolumn{2}{|c|}{ Chi-Square } \\
\hline & $N$ & $\%$ & $N$ & $\%$ & $\overline{X^{2}}$ & $P$ value \\
\hline \multicolumn{7}{|l|}{ Interatrial septum } \\
\hline Intact & 10 & 33.33 & 10 & 33.33 & 1.043 & 0.959 \\
\hline Secondum ASD & 12 & 40.00 & 11 & 36.67 & & \\
\hline PFO & 5 & 16.67 & 5 & 16.67 & & \\
\hline Septum prmium ASD & 2 & 6.67 & 2 & 6.67 & & \\
\hline Superior sinus venousus ASD & 1 & 3.33 & 1 & 3.33 & & \\
\hline Hard to interpertate & 0 & 0.00 & 1 & 3.33 & & \\
\hline Total & 30 & 100.00 & 30 & 100.00 & & \\
\hline \multicolumn{7}{|l|}{ Interventricular septum } \\
\hline Intact & 12 & 40.00 & 11 & 36.67 & 2.120 & 0.908 \\
\hline Perimembranous VSD & 8 & 26.67 & 8 & 26.67 & & \\
\hline Subaortic VSD & 7 & 23.33 & 6 & 20.00 & & \\
\hline Muscular VSD & 1 & 3.33 & 1 & 3.33 & & \\
\hline Atrioventricular canal type & 1 & 3.33 & 1 & 3.33 & & \\
\hline Hard to interpertate & 0 & 0.00 & 2 & 6.67 & & \\
\hline Subaortic VSD \& Muscular VSD & 1 & 3.33 & 1 & 3.33 & & \\
\hline Total & 30 & 100.00 & 30 & 100.00 & & \\
\hline
\end{tabular}

Table 5 Aortic anomalies detected by Echocardiography and MDCT angiography

\begin{tabular}{|c|c|c|c|c|}
\hline \multirow[t]{2}{*}{ Aortic anomalies } & \multicolumn{2}{|c|}{$\mathrm{ECHO}$} & \multicolumn{2}{|c|}{ MDCT } \\
\hline & $N$ & $\%$ & $N$ & $\%$ \\
\hline TGA & 5 & 16.67 & 5 & 16.67 \\
\hline Overriding & 6 & 20.00 & 6 & 20.00 \\
\hline Coarctation & 3 & 10.00 & 4 & 13.33 \\
\hline Hypoplastic segment & 2 & 6.67 & 4 & 13.33 \\
\hline Interrupted aorta & 1 & 3.33 & 1 & 3.33 \\
\hline Truncus arteriosus & 3 & 10.00 & 3 & 10.00 \\
\hline Aortic valve stenosis & 1 & 3.33 & 1 & 3.33 \\
\hline Right sided aortic arch & 1 & 3.33 & 4 & 10.00 \\
\hline
\end{tabular}

MDCT angiography was superior to Echocardiography in assessment of extra cardiac aortic anomalies, Echocardiography missed aortic coarctation in one case which was similar to Al-Azzazy et al. [19], they reported that Echocardiography missed two cases of coarctation in their study from 24 cases of aortic coarctation with significant difference between Echocardiography and cardiac MDCT in the detection of aortic coarctation.

Echocardiography in the current study missed detection of two cases of hypoplastic segment of the aorta which came close to Eltatawy et al. [22], they missed detection of two cases of aortic arch hypoplasia.

Table 6 Aortic anomalies detected by MDCT angiography compared to surgical and or cardiac catheterization

\begin{tabular}{|c|c|c|c|c|c|c|c|c|c|}
\hline Aortic anomalies & TP & FP & TN & $\mathrm{FN}$ & Sensitivity & Specifity & PPV & NPV & Accuracy \\
\hline Overriding & 6 & 0 & 24 & 0 & 100.0 & 100.0 & 100.0 & 100.0 & 100.0 \\
\hline TGA & 5 & 0 & 25 & 0 & 100.0 & 100.0 & 100.0 & 100.0 & 100.0 \\
\hline Truncus arteriosus & 3 & 0 & 27 & 0 & 100.0 & 100.0 & 100.0 & 100.0 & 100.0 \\
\hline IAA & 1 & 0 & 29 & 0 & 100.0 & 100.0 & 100.0 & 100.0 & 100.0 \\
\hline Coarctation & 4 & 0 & 26 & 0 & 100.0 & 100.0 & 100.0 & 100.0 & 100.0 \\
\hline Right side aortic arch & 4 & 0 & 26 & 0 & 100.0 & 100.0 & 100.0 & 100.0 & 100.0 \\
\hline Aortic valve stenosis & 1 & 0 & 28 & 1 & 50.0 & 96.5 & 100.0 & 96.5 & 96.67 \\
\hline Hypoplastic segment & 4 & 0 & 26 & 0 & 100.0 & 100.0 & 100.0 & 100.0 & 100.0 \\
\hline Total & 28 & 0 & 211 & 1 & 93.7 & 99.56 & 100.0 & 99.56 & 99.58 \\
\hline
\end{tabular}


Table 7 Right, left, and main pulmonary arteries abnormalities detected by Echocardiography and MDCT angiography

\begin{tabular}{|c|c|c|c|c|c|c|}
\hline & \multicolumn{2}{|c|}{ ECHO } & \multicolumn{2}{|c|}{ MDCT } & \multicolumn{2}{|c|}{ Chi-square } \\
\hline & $N$ & $\%$ & $N$ & $\%$ & $\overline{x^{2}}$ & $P$ value \\
\hline \multicolumn{7}{|l|}{ Right pulmonary } \\
\hline Normal & 22 & 73.13 & 13 & 43.33 & 8.157 & $0.043^{*}$ \\
\hline Dilated & 4 & 13.33 & 7 & 23.33 & & \\
\hline Hypoplastic & 4 & 13.33 & 7 & 23.33 & & \\
\hline Osteal stenosis & 0 & 0.00 & 3 & 10.00 & & \\
\hline Total & 30 & 100.00 & 30 & 100.00 & & \\
\hline \multicolumn{7}{|l|}{ Left pulmonary } \\
\hline Normal & 21 & 70.00 & 11 & 36.67 & 7.799 & $0.050^{*}$ \\
\hline Dilated & 5 & 16.67 & 7 & 23.33 & & \\
\hline Hypoplastic & 3 & 10.00 & 8 & 26.67 & & \\
\hline Osteal stenosis & 1 & 3.33 & 4 & 13.33 & & \\
\hline Total & 30 & 100.00 & 30 & 100.00 & & \\
\hline \multicolumn{7}{|l|}{ MPA } \\
\hline Normal & 17 & 56.67 & 12 & 40.00 & 3.363 & 0.499 \\
\hline Dilated & 6 & 20.00 & 7 & 23.33 & & \\
\hline Hypoplastic & 5 & 16.67 & 6 & 20.00 & & \\
\hline Subpulmonic stenosis & 0 & 0.00 & 1 & 3.33 & & \\
\hline Absent & 2 & 6.67 & 4 & 13.33 & & \\
\hline Total & 30 & 100.00 & 30 & 100.00 & & \\
\hline
\end{tabular}

* significant $p$ value $(<0.05)$

Table 8 Findings of congenital pulmonary artery anomalies by MDCT angiography compared to surgical and or cardiac catheterization results

\begin{tabular}{|c|c|c|c|c|c|c|c|c|c|}
\hline & $\mathrm{TP}$ & FP & TN & FN & Sensitivity & specifity & PPV & NPV & Accuracy \\
\hline \multicolumn{10}{|c|}{ Pulmonary stenosis } \\
\hline MPA & 1 & 0 & 29 & 0 & 100.0 & 100.0 & 100.0 & 100.0 & 100.0 \\
\hline LPA & 3 & 0 & 27 & 0 & 100.0 & 100.0 & 100.0 & 100.0 & 100.0 \\
\hline RPA & 4 & 0 & 25 & 1 & 80.0 & 100.0 & 100.0 & 96.1 & 96.67 \\
\hline MPA artesia & 4 & 0 & 26 & 0 & 100.0 & 100.0 & 100.0 & 100.0 & 100.0 \\
\hline \multicolumn{10}{|c|}{ Pulmonary hypoplasia } \\
\hline MPA & 6 & 0 & 24 & 0 & 100.0 & 100.0 & 100.0 & 100.0 & 100.0 \\
\hline LPA & 7 & 0 & 22 & 1 & 87.5 & 100.0 & 100.0 & 95.65 & 96.67 \\
\hline RPA & 8 & 0 & 21 & 1 & 88.89 & 100.0 & 100.0 & 95.65 & 96.67 \\
\hline \multicolumn{10}{|c|}{ Pulmonary dilation } \\
\hline MPA & 7 & 0 & 23 & 0 & 100.0 & 100.0 & 100.0 & 100.0 & 100.0 \\
\hline LPA & 7 & 0 & 23 & 0 & 100.0 & 100.0 & 100.0 & 100.0 & 100.0 \\
\hline RPA & 7 & 0 & 23 & 0 & 100.0 & 100.0 & 100.0 & 100.0 & 100.0 \\
\hline Total & 54 & 0 & 243 & 3 & 95.6 & 100.0 & 100.0 & 98.7 & 99.0 \\
\hline
\end{tabular}

Demonstration of the origin of coronary arteries may be part of the routine workup for patients with PDA undergo diagnostic evaluation and therapeutic interventions [25].

In the present study we detected coronary anomalies in $3(10 \%)$ cases ( 2 had single coronary artery arise from right coronary cusp and 1 case had ectatic left coronary artery) which was similar to study did by Dotan et al. [25], they reported (10.8\%) anomalous origin of coronary artery associated with PDA.

Abd El-Gaber et al. [26] reported atresia (absence) of the main pulmonary artery (14 cases $\backslash 33.3 \%$ ) was the 
Table 9 Descriptive analysis of the studied cases according to DLP and effective dose reduction in each age group

\begin{tabular}{lrll}
\hline Age (months) & No & DLP & $\begin{array}{l}\text { Effective } \\
\text { dose } \\
\text { reduction } \\
\text { Mean } \pm \text { SD }\end{array}$ \\
\hline$<4$ months & 18 & $77.83 \pm 21.89$ & $3.02 \pm 0.85$ \\
$\geq 4$ to $<12$ months & 8 & $65.99 \pm 11.76$ & $1.80 \pm 0.27$ \\
$\geq 12$ months to $<6$ years & 2 & $87.90 \pm 20.87$ & $1.58 \pm 0.38$ \\
$\geq 6$ years & 2 & $238.9 \pm 282.3$ & $3.33 \pm 3.92$ \\
Total & 30 & $91.79 \pm 88.45$ & $2.61 \pm 1.38$ \\
\hline
\end{tabular}

commonest encountered type of pulmonary artery anomalies associated with PDA. However, we reported main pulmonary artery atresia in 4 (13.33\%) out of 18 cases, dilated MPA in 7 (23.33\%) cases, MPA hypoplasia in $6(20 \%)$ cases, subpulmonic stenosis in 1 (3.33\%) case.

Chi square test in the current study revealed non statistically significant difference between both Echocardiography and MDCT angiography in detection of main pulmonary artery anomalies $(P=0.49)$ but revealed statistically significant difference between both Echocardiography and MDCT angiography in detection of left pulmonary artery and right pulmonary artery anomalies $(P=0.05$ for left pulmonary artery and $P=0.043$ for right pulmonary artery).This came in agreement with Liu et al. [27], they missed detection of MPA anomalies in 7 cases, 46 cases of RPA and LPA anomalies by Echocardiography due to restricted acoustic windows and operator dependency. Also agreed with Chandrashekhar et al. [8], they also reported failure of Echocardiography to visualize 3 cases of MPA anomalies, 6 cases of RPA anomalies and 2 cases of LPA anomalies due to limited acoustic windows, low spatial resolution and structures are obscured by overlying bone and aerated lung.

The relatively small numbering of the studied cases was our major limitation in this study that not giving full idea about the diagnostic efficacy of cardiac MDCT.

\section{Conclusion}

Cardiac MDCT angiography was superior to Echocardiography in detection, quantitative and qualitative evaluation of PDA either isolated or associated with congenital cardiac and $\backslash$ or extracardiac anomalies and was superior to Echocardiography in detection of associated extracardiac anomalies rather than associated intra cardiac anomalies.

We recommended that patients should be carefully selected for CT imaging, and strategies for radiation exposure reduction need to be applied. Increasing the sample size in the future is recommended.

\begin{abstract}
Abbreviations
ASD: Atrial septal defect; CHD: Congenital heart disease; CHF: Congestive heart failure; CMRI: Cardiac magnetic resonance imaging; CoA: Aortic coarctation; CPR: Curved planer reformation; DLP: Dose length product; EA: Ebstein's anomaly; IA: Innominate artery; IAA: Interrupted aortic arch; MDCT: Multi-detector computed tomography; MIP: Maximum intensity projections; MPA: Main pulmonary artery; PA: Pulmonary artery; PAPVR: Partial anomalous pulmonary venous return; PDA: Patent ductus arteriosus; TAPVR: Total anomalous pulmonary venous return; TGA: Transposition of the great arteries; TOF: Tetralogy of fallot; VR: Volume rendering; VRT: Volume rendered technique;
\end{abstract} VSD: Ventricular septal defect.

\section{Acknowledgements}

To all the participants for their cooperation and patience.

\section{Authors' contributions}

MD suggested the research idea, ensured the original figures and data in the work, minimized the obstacles to the team of work, correlated the study concept and design and had the major role in analysis, SG collected data in all stages of manuscript, performed data analysis. MY supervised the study with significant contribution to design the methodology, manuscript revision and preparation. ES correlated the clinical data of patient and matched it with the findings, drafted and revised the work. All authors read and approved the final manuscript for submission. All authors read and approved the final manuscript for submission.

Funding

No funding. Not applicable for this section.

\section{Availability of data and materials}

The author's confirm that all data supporting the finding of the study are available within the article and the raw data ad data supporting the findings were generated and available at the corresponding author on request.

\section{Declarations}

\section{Ethics approval and consent to participate}

Informed written consents taken from the patients and healthy volunteers, the study was approved by ethical committee of Tanta university hospital, faculty of medicine. Committee's reference number: 33678/2/20.

\section{Consent for publication}

All participants included in the research gave written consent to publish the data included in the study.

\section{Competing interests}

The authors declare that they have no competing of interests.

Received: 16 August 2021 Accepted: 5 October 2021

Published online: 12 October 2021

\section{References}

1. Maldonado JA, Henry T, Gutierrez FR (2012) Congenital thoracic vascular anomalies. Radiol Clin N Am 48:85-115. https://doi.org/10.1016/j.rcl.2009. 09.004

2. Boutsikou M, LiW (2018) Echocardiography. In: Gatzoulis MA, Webb WG, Daubeney $\mathrm{E}$ (eds) Diagnosis and management of adult congenital heart disease, 3rd edn. Elsevier, Amsterdam, pp 41-76

3. Chylman R (2011) PDA in preterm infant. In: Gleason C (ed) Avery's diseases of Newborn (9th edition). Elsevier, Amsterdam, pp 751-761

4. Moccetti F, Kaufman B, Tobler D (2014) Differential clubbing and cyanosis: pathognomonic finding in cardiology. Eur Heart J 35:1410. https://doi. org/10.1093/eurheartj/ehu020 
5. Cucerea M, Simon M, Moldovan E et al (2016) Congenital heart disease requiring maintenance of ductus arteriosus in critically newborns. J Crit Care Med 4:185-191. https://doi.org/10.1515/jccm-2016-0031

6. Siripornpitak S, Pornkul R, Khowsathit P (2013) Cardiac CT angiography in children with congenital heart disease. Eur J Radiol 82(7):1067-1082. https://doi.org/10.1016/j.ejrad.2011.11.042

7. Lee T, Tsai IC, Fu YC et al (2006) Using multidetector-row CT in neonates with complex congenital heart disease to replace diagnostic cardiac catheterization for anatomical investigation: Initial experiences in technical and clinical feasibility. Pediatr Radiol 36(12):1273-1282. https://doi. org/10.1007/s00247-006-0315-y

8. Chandrashekhar G, Sodhi KS, Saxena AK et al (2012) Correlation of 64 row MDCT, echocardiography and cardiac catheterization angiography in assessment of pulmonary arterial anatomy in children with cyanotic congenital heart disease. Eur J Radiol 12:4211-4217. https://doi.org/10. 1016/j.ejrad.2012.08.010

9. Haramati LB, Glickstein JS, Issenberg HJ, (2002) MR imaging and CT of vascular anomalies and connections in patients with congenital heart disease: significance in surgical planning. Radiographics 22(2):337-347. https://doi.org/10.1148/radiographics.22.2.g02mr09337

10. Morgan HJ, Marshall AJ, Roobottom C (2003) Morphological assessment of patent ductus arteriosus in adult using retrospectively ECG-gated multidetector CT. Am J Roentgenol 181(3):749-754. https://doi.org/10. 2214/ajr.181.3.1810749

11. Driessen MM, Breur JM, Budde RP (2015) Advances in cardiomagnetic resonance imaging of congenital heart disease. Pediatr Radiol 45(1):5-19. https://doi.org/10.1007/s00247-014-3067-0

12. Simpson JM, Moore P, Teitel DF (2001) Cardiac catheterization of low birth weight infants. Am J Cardiol 87(12):1372-1377. https://doi.org/10.1016/ s0002-9149(01)01555-7

13. Krupinski M, Irzyk M, Moczuliski Z et al (2020) Detailed radiological study of patent ductus arteriosus: a computed tomography study in polish population. Folia Morphol J 79(3):462-468. https://doi.org/10.5603/FM. a2019.0116

14. Taylor AM (2008) Cardiac imaging: MR or CT? Which to use when. Pediatr Radiol 38:433-438. https://doi.org/10.1007/s00247-008-0843-8

15. Krichenko A, Benson LN, Burrows P et al (1989) Angiographic classification of the isolated, persistently patent ductus arteriosus and implications for percutaneous catheter occlusion. Am J Cardiol 63(12):877-880. https://doi.org/10.1016/0002-9149(89)90064-7

16. Seif-El Dien HM, Ibrahim LA, Hashem RH (2014) Evaluation of aortic arch anomalies by echocardiography and CT angiography, could CT be the primary method of diagnosis? Brit J Med Med Res 4(16):3179-3195. https://doi.org/10.9734/BJMMR/2014/8932

17. Ntsinjana HN, Hughes ML, Taylor AM (2011) The role of cardiovascular magnetic resonance in pediatric congenital heart disease. J Cardiovasc Magn Reson 13(1):1-20. https://doi.org/10.1186/1532-429X-13-51
18. Harraz MM, Abouissa AH, Saleh HA et al (2019) MDCT angiographic findings of various congenital pulmonary artery anomalies in pediatric patients. Egypt J Radiol Nuclear Med 5:1-13. https://doi.org/10.1186/ s43055-019-0089-5

19. Al-azzazy MZ (2014) Multidetector computed tomography (MDCT) angiography of thoracic aortic coarctation in pediatric patients: pre-operative evaluation. Egypt J Radiol Nuclear Med 45(1):159-167. https://doi.org/10. 1016/j.ejrnm.2013.10.003

20. Hu BY, Shi K, Deng YP et al (2017) Assessment of tetralogy of Fallot-associated congenital extracardiac vascular anomalies in pediatric patients using low-dose dual-source computed tomography. BMC Cardiovasc Disord 17(1):1-8. https://doi.org/10.1186/s12872-017-0718-8

21. Nie P, Yang G, Wang X et al (2014) Application of prospective ECG-gated high-pitch 128-slice dual-source CT angiography in the diagnosis of congenital extracardiac vascular anomalies in infants and children. PLoS ONE 9(12):1-14. https://doi.org/10.1371/journal.pone.0115793

22. Eltatawy DN, Elsharawy FA, Elbarbay AA et al (2021) Multidetector computed tomography (MDCT) as a diagnostic tool in assessment of thoracic aortic anomalies in pediatric patients. Egypt J Radiol Nuclear Med 52(1):1-10. https://doi.org/10.1186/s43055-020-00399-5

23. YI L, Liang CD, Fang CY et al (2010) Multidetector-row CT evulation of torsious ducts arteriosus for stent implanation in neonates with duct dependant pulmonary circulation: preliminary experience in 4 caes. Acta Cardiol Sin 26:111-118

24. Enaba MM, Hasan DI, Alsowey AM et al (2017) Multidetector computed tomography (CT) in evaluation of congenital cyanotic heart diseases. Polish J Radiol 82:645-659. https://doi.org/10.12659/PJR.903222

25. Dotan M, Roguin A, Sinyor D et al (2013) Increased incidence of coronary artery origin anomalies associated with isolated patent ductus arteriosus. Pediatr Cardiol 34(4):907-911. https://doi.org/10.1007/s00246-012-0569-0

26. Abd El-Gaber N, Alsawah GA (2013) Role of 16-multidetector CT angiography in assessment of arterial and venous pulmonary anomalies in pediatrics. Egypt J Radiol Nuclear Med 44(3):483-495. https://doi.org/10. 1016/j.ejrnm.2013.05.011

27. Liu J, Li H, Liu Z et al (2016) Complete preoperative evaluation of pulmonary atresia with ventricular septal defect with multi-detector computed tomography. PLoS ONE 11(1):1-12. https://doi.org/10.1371/journal.pone. 0146380

\section{Publisher's Note}

Springer Nature remains neutral with regard to jurisdictional claims in published maps and institutional affiliations.

\section{Submit your manuscript to a SpringerOpen ${ }^{\circ}$ journal and benefit from:}

- Convenient online submission

- Rigorous peer review

- Open access: articles freely available online

- High visibility within the field

Retaining the copyright to your article

Submit your next manuscript at springeropen.com 